\title{
No risky shift effect with real groups and real risks
}

DAVID E. CLEMENT and DALE W. SULLIVAN, University of South Florida, Tampa, Fla. 33620

Five discussion sections of an introductory psychology course (containing 16-18 students each) were asked to select an examination schedule from a set of eight alternatives. The choices had been scaled by students in a previous course on a risk-safety continuum and were selected for maximum dispersion on the continuum as well as for consistency in placement on the continuum. Individual preferences for schedule were obtained both before and after the group decision. Four of five groups shifted in a conservative direction from the average of initial individual choices. $A$ significant proportion (.9) of those Ss who changed their individual preferences after discussion shifted in a conservative direction. The results suggest that the "risky-shift" effect is an artifact of the laboratory conditions under which it has been obtained.

The tendency for group decisions after discussion to be more risky than the average of prior individual decisions has been labeled the "risky-shift" effect (see Kogan \& Wallach, 1967, for a lucid discussion). Several investigators (e.g., Stoner, 1961; Wallach, Kogan, \& Bem, 1962) have obtained risky shifts under varying conditions, basically using hypothetical problems with small groups (three to six members of one sex), which were required to discuss each problem until a consensus was reached. Marquis (1962) and Wallach \& Kogan (1965) obtained a risky shift without requiring discussion to consensus, Teger \& Pruitt (1967) found the magnitude of the risky shift to increase with increasing group size, and Jamieson (1968) obtained risky shifts using various $S$ populations, indicating at least some generality to the phenomenon. A few studies (e.g., Zajonc, Wolosin, Wolosin, \& Sherman, 1968) have obtained conservative shifts, and Nordhoy (1962) suggested that the direction of the shift is problem-specific. Other studies, which obtained no shift or varied shifts, led to suggestions that the occurrence and direction of a shift are influenced by the amount of time for discussion (Hunt \& Rowe, 1960), the differences perceived among the alternative choices (Rabow, Fowler, Bradford, Hofeller, \& Shibuya, 1966), the relative probabilities of success among the choices (Zajonc et al, 1969), and the Ss' values and self-perceptions
(Stoner, 1968). Only one finding has been consistent. In all studies where such measures were obtained, individual choices after a group decision showed shifts in the same direction as the group choice, indicating a true change in choice rather than simple acquiescence to the majority.

Only a few studies have involved "real" risks as opposed to hypothetical risks. Wallach, Kogan \& Bem (1964) used groups of three males or three females who could win varying amounts of money, depending upon the difficulty level of questions they chose to answer. A risky shift was obtained when the group discussed the situation prior to choosing the level of question difficulty, under conditions where the expected value of their decision was approximately the same for all choices. Unfortunately, the riskiest choice had a slightly higher expected value than the other choices, although the investigators did not feel this affected the results. Bem, Wallach, \& Kogan (1965) used anticipated noxious physical side-effects as negative risk values in a task where Ss chose among stimulus situations that might result in such effects. The amount of potential pay increased and the probability of the pay decreased as the probability and severity of noxious side-effects increased. A risky shift was obtained, despite the fact that the expected value of the choice increased slightly with decreasing risk. Both of these studies are open to the criticism that the Ss may not have perceived the risks as real. In the Wallach, Kogan, \& Bem (1964) experiment, the money risked belonged to the E, and Edwards (1953) suggested that such money may be valued differently from money that was the S's own. Edwards found a preference for riskier gambles when the $\mathrm{S}$ used his own money, but this was comparable to the individual choices made before discussion in the group-decision studies. No experimental study has used group decisions involving money belonging to members of the group. In the Bem, Wallach, \& Kogan (1965) study, the Ss may not have thought that the noxious side effects would really be as bad as purported, or they may have guessed that they would not be subjected to such effects (and, in fact, they were not).

Explanations of the apparent risky-shift phenomenon have included diffusion of responsibility among members of the group (Bem, Wallach, \& Kogan, 1965), a general "choice-shift" effect (Levinger \& Schneider, 1969), the effect of relative amounts of information concerning available choices that are discussed by the group (Brown, 1965), increased comprehension of the choices (Flanders \& Thistlethwaite, 1967), and a change in the social perception of the relative value of risk-taking (Brown, 1965; Teger \& Pruitt, 1967; Wallach \& Wing, 1968). Although interesting, all these hypotheses are of little practical value if the risky shift is an artifact of the relatively meaningless situations under which it has been obtained. If the Ss do not feel involved in an important decision, other factors, such as those suggested, might play a greater role than they would for decisions that the Ss perceived as relatively meaningful.

No published study has dealt with decisions of the type discussed above, involving risk, in "real-world" (i.e., normally occurring) situations. This study was designed to investigate group decision-making under one such situation. SUBJECTS

Eight-five students ( 47 male, 38 female) in an introductory psychology course were used as Ss. All Ss met three times per week for mass lectures and once per week in small discussion sections. The number of Ss in each discussion section was as follows: Group 1, 17 Ss (6 male, 11 female); Group 2, 18 Ss (9 male, 9 female); Group 3, 16 Ss (12 male, 4 female); Group 4, 16 Ss (10 male, 6 female); Group 5, 18 Ss (10 male, 8 female). Students were assigned to discussion sections in strict sequence at registration, minimizing the number of close friends who were in the same group.

\section{DECISION CHOICES}

A group of 100 students from a previous introductory psychology course was used to obtain subjective risk values for each of 30 different examination schedules for the course (e.g., one test at completion of the course, three tests on exclusive units of the course, etc.). The examination schedules were ranked in terms of riskiness (defined as "possibility of receiving a final grade higher than deserved but at the risk of receiving a grade lower than deserved") and independently in terms of safety (defined as "possibility of not receiving a grade lower than deserved"). The rankings were used to select eight examination schedules that had high consensual agreement as to risk or safety value, and that were dispersed as uniformly as possible over the risk-safety continuum. These were designated for the present experiment as Choices 1-8, with 1 being the riskiest choice and 8 being the safest, or most conservative, choice.

\section{PROCEDURE}

During the first lecture meeting of the course (prior to any meetings of discussion sections), each $\mathbf{S}$ was given a form listing 
the eight examination schedules and was asked to chouse one preferred schedule. It was explained that this indication of preference was to be used in determining the actual schedule for the course. The forms were signed and identified by student number, under the guise of checking the accuracy of the class roll. At the first discussion-section meeting, the Ss were told that they had indicated diverse preferences and that it had been decided to allow the individual discussion sections to select their own examination schedules. The instructor for each section (a graduate student) told them to discuss the choices and decide which they preferred. No other instructions were given as to how to reach that decision. The Ss knew that they were limited by the $50-\mathrm{min}$ class period, but they were not told that the instructor would interrupt if discussion lasted more than $30 \mathrm{~min}$. During the discussion-group meeting of the following week, the Ss were given a questionnaire requesting their currently preferred examination schedule, their original preference and group decision, and other opinions concerning the procedures used in determining the schedule. As the examination schedules had been posted before this meeting, all were aware that the decision of their group was being implemented. Ss signed the questionnaires, allowing a check on the accuracy of their recall of their original preferences.

\section{RESULTS}

The private choices before discussion were all from the conservative half of the eight choices presented (see Table 1), with all but five Ss choosing either 6 or 8 . All five groups contained a majority of Ss whose individual preference was Choice 6 prior to discussion, yet four of these groups selected Choice 8 , the most conservative choice. The individual choices shifted similarly. None of the 32 Ss whose group's choice agreed with their own initial private choice changed that private choice. Of the other 53 Ss whose initial private choice differed from the group choice, 32 changed their own preferences -29 in the conservative direction and 3 in the risky direction, all shifting toward the choice of their own group. These last proportions of

Table 1

Private Choices of Examination Schedule Before and After Discussion and Group Choices After Discussion

Frequency of Private Choice

\begin{tabular}{|c|c|c|c|c|c|c|c|}
\hline \multirow[b]{3}{*}{ Group } & \multirow{3}{*}{$\begin{array}{l}\text { Group } \\
\text { Choice }\end{array}$} & & & & & & \\
\hline & & \multicolumn{4}{|c|}{ Before Discussion } & \multicolumn{2}{|c|}{ After Discussion } \\
\hline & & $\mathrm{v}$ & VI & VII & VIII & VI & VIII \\
\hline 1 & VIII & - & 10 & 1 & 6 & 6 & 11 \\
\hline 2 & VIII & 1 & 10 & - & 7 & 5 & 13 \\
\hline 3 & VIII & - & 11 & - & 5 & 3 & 13 \\
\hline 4 & VI & - & 10 & 1 & 5 & 13 & 3 \\
\hline 5 & VIII & 1 & 12 & 1 & 4 & 4 & 14 \\
\hline
\end{tabular}

The conservatism of the original individual choices is of some interest in view of Edwards's (1953) results. One hypothesis might be that students are conservative with grades, while they are risky with small amounts of money because of the subjective values attached (e.g., one might reason, "I can always earn another \$2, no matter how poor I am, but I'm stuck with a poor grade on my record forever"). The original choices were clustered at the conservative end of the examination schedules and, thus, served as limits or end anchors. This might be expected to shift preferences toward Choice 6 after discussion, making the obtained conservative shift even more impressive.

Unlike the earlier studies that obtained risky shifts, this study used groups that were formed in a natural setting for purposes other than conduct of an experiment. The problem and decision choices were perceived as real and appropriate by all $\mathrm{Ss}$, as were the risks involved. It is reasonable to assume that, insofar as examinations affect grades, the examination schedule was of some importance to the Ss, most of whom are under continual stress to obtain high grades. Other factors in this study that differed from most of the prior literature were the inclusion of $S s$ of both sexes in the discussion groups, and the use of moderately large discussion groups (16-18 members). These differences should be in the direction of greater similarity to natural group decision-making, and lend more interest to the divergence of the results from those previously obtained.

The experimental circumstances seem adequate to assure a risky shift (large group size, a majority of Ss choosing the riskier of two modal choices before discussion, etc.). Nevertheless, a conservative shift was obtained for a significant proportion of the Ss who changed their initial choices, and for four of five group dicisions. The occurrence of a conservative shift in this realistic situation suggests the tenuous nature of the risky-shift effect, and supports the hypothesis that the risky shift is an artifact of the laboratory conditions under which it has occurred.

\section{REFERENCES}

BEM, D. J., WALLACH, M. A., \& KOGAN, N. Group decision making under risk of aversive consequences. Journal of Personality \& Social Psychology, 1965, 1, 453-460.

BROWN, R. Social psychology. New York: Free Press, 1965.

EDWARDS, W. Probability preferences in gambling. American Joumal of Psychology, 1953, 66, 349-364.

FLANDERS, J. P., \& THISTLETHWAITE, D. L. Effects of familiarization and group discussion upon risk taking. Journal of Personality \& Social Psychology, 1967, 5, 91-97. 
HUNT, E. B., \& ROWE, R. R. Group and individual economic decision making in risk conditions. In D. W. Taylor (Ed.), Experiments on decision making and other studies. Arlington, Va.: Armed Services Technical Information Agency, 1960. (Technical Report No. 6, AD 253952.)

JAMIESON, B. D. The "risky-shift" phenomenon with a heterogeneous sample. Psychological Reports, 1968, 23, 203-206.

KOGAN, N., \& WALLACH, M. A. Risk taking as a function of the situation, the person, and the group. In New directions in psychology III. New York: Holt, Rinehart, \& Winston, 1967.

LEVINGER, $\mathrm{G}_{*}$ \& SCHNEIDER, D. J. Test of the "risk is a value" hypothesis. Journal of Personality \& Social Psychology, 1969, 11, 165-169.

MARQUIS, D. G. Individual responsibility and group decisions involving risk. Industrial Management Review, 1962, 3, 8-23.

NORDHФY, F. Group interaction in decision-making under risk. Unpublished Master's thesis, Massachusetts institute of Technology, School of Industrial Management, 1962.

RABOW, J., FOWLER, JR., F. J., BRADFORD, D. L., HOFELLER, M. A., \& SHIBUYA, Y. The role of social norms and leadership in risk-taking. Sociometry, 1966, 29, 16-27.

STONER, J. A. F. A comparison of individual and group decisions involving risk. Unpublished Master's thesis, Massachusetts
Institute of Technology, School of Industrial Management, 1961.

STONER, J. A. F. Risky and cautious shifts in group decisions: The influence of widely held values. Journal of Experimental Social Psychology, 1968, 4, 442-459.

TEGER, A. I., \& PRUITT, D. G. Components of group risk taking. Journal of Experimental Social Psychology, 1967, 3, 189-205.

WALLACH, M. A., \& KOGAN, N. The roles of information, discussion, and consensus in group risk taking. Journal of Experimental Social Psychology, 1965, 1, 1-19.

WALLACH, M. A., KOGAN, N., \& BEM, D. J. Group influence on individual risk taking. Journal of Abnormal \& Social Psychology, $1962,65,75-86$.

WALLACH, M. A., KOGAN, N., \& BEM, D. J. Diffusion of responsibility and level of risk taking in groups. Joumal of Abnormal \& Social Psychology, 1964, 68, 263-274.

WALLACH, M. A., \& WING, JR., C. W. Is risk a value? Joumal of Personality \& Social Psychology, 1968, 9, 101-106.

ZAJONC, R. B., WOLOSIN, R. J., WOLOSIN, M. A., \& SHERMAN, S. J. Individual and group risk taking in a two-choice situation. Joumal of Experimental Social Psychology, 1968, 4, 89-106.

ZAJONC, R. B., WOLOSIN, R. J., WOLOSIN, M. A., \& SHERMAN, S. J. Group risk-taking in a two-choice situation: Replication, extension, and a model. Joumal of Experimental Social Psychology, 1969, 5, 127-140.

\section{Effects of the value of contingent self-}

\section{administered and noncontingent externally imposed reward on children's behavioral productivity}

ROBERT M. LIEBERT, Fels Research Institute, Yellow Springs, Ohio 45387, MICHAEL D. SPIEGLER, Palo Alto V.A. Hospital, Palo Alto, Calif. 94304, and Wm. MICHAEL HALL, Indiana University, Bloomington, Ind. 47401

Children's behavioral productivity as a function of method of reward (contingent self-administered vs noncontingent externally imposed) and exchange value of token rewards (none, low, and high) was examined in a 2 by 3 factorial design. Ss were required to set their own standards and to turn a crank in order to reach them. Contingent-reward $S$ s self-administered tokens whenever their self-imposed standards were attained, while noncontingent-reward $S$ s received tokens during the course of their play and were yoked to $S s$ in the contingent condition with respect to the number of tokens received. The productivity of children who received exchangeable tokens exceeded that of control Ss who received no tokens, and the number of cranks produced during the 4-min performance period was directly related to the value of the token rewards for both contingently and noncontingently rewarded $S s$. Ss in the latter group changed their standards significantly more often than those in the former, suggesting that they were responding "superstitiously" to the administration of reward.

Bandura \& Perloff (1967), employing a task that permitted 7 - to 10 -year-old children to set their own standards and administer reward tokens to themselves for having attained their standards, found self-administered and externally controlled reward to be equally potent in inducing behavioral productivity. Moreover, Ss in both of these conditions exhibited significantly more productivity than did those in control groups. The major purpose of the present experiment was to test the hypothesis that the influence of self-administered reward on behavioral productivity would vary directly with the ascribed value of the available reward tokens. Additionally, whereas Bandura and Perloff's noncontingent reward controls received their tokens in a lump sum before playing the game (i.e., as an "inheritance"), Ss rewarded noncontingently in the present study received tokens during the course of their performance. Finally, since life situations often limit the total amount of time available for a given task, all Ss were allotted a fixed period of performance time instead of being permitted to persist as long as they wished (cf. Bandura \& Perloff).

\section{DESIGN AND PARTICIPANTS}

The Ss were 64 children ( 32 boys and 32 girls), 7-10 years of age, from two elementary schools in a lower-middle-class area of Nashville, Tennessee. The same adult female served as E for all Ss. A 2 by 3 factorial design was employed, with the factors being method of reward (contingent self-reward and noncontingent externally controlled reward) and reward value of the available tokens (none, low, and high). Four boys and four girls were assigned randomly to each of the experimental cells. Ss in two control groups, each consisting of four boys and four girls, received no tokens. These latter groups differed from each other only in that for one a chime was sounded each time $\mathrm{S}$ reached his self-imposed standard, while in the other it was not.

\section{APPARATUS}

The "standard setter" apparatus consisted of a 3-ft-high triangular box on which two vertical columns of 20 adjacent pairs of miniature lights were displayed. Next to each fifth pair of lights, the scores " 5 ," " 10 ," " 15 ," and " 20 " were printed in 